\title{
Assessing the productive vocabulary of Spanish-English bilingual toddlers from low-income families
}

\author{
JEANNETTE MANCILLA-MARTINEZ \\ University of Illinois at Chicago \\ BARBARA ALEXANDER PAN and SHAHER BANU VAGH \\ Harvard Graduate School of Education
}

Received: August 30, 2008 Accepted for publication: February 9, 2010

\author{
ADDRESS FOR CORRESPONDENCE \\ Jeannette Mancilla-Martinez, University of Illinois at Chicago, College of Education, 1040 West \\ Harrison Street (MC 147), Room 3042, Chicago, IL 60607. E-mail: jmm25@uic.edu
}

\begin{abstract}
This study investigates the utility and validity of the MacArthur-Bates Communicative Development Inventory (CDI) for use with low-income parents and their 24- to 36-month-old Spanish-English bilingual children $(n=79)$. Issues in the interpretation of the integrated CDI/Inventarios del Desarrollo de Habilidades Comunicativas (IDHC) score to index bilingual children's overall conceptual knowledge are also considered. Results indicate that the CDI/IDHC can be used with this population through at least age 36 months and parents are accurate reporters of their children's Spanish and English vocabulary. The value of the integrated score was confirmed. However, given the lack of norms associated with the integrated score, the complexity of determining how best to interpret this score was underscored.
\end{abstract}

Converging evidence indicates that language minority learners in the United States are at greater risk for school failure than monolingual English speakers, with a low level of vocabulary repeatedly identified as a key impediment to school success (August \& Shanahan, 2006; National Institute of Child Health and Human Development, 2000; Snow, Burns, \& Griffin, 1998). Further, low socioeconomic status is also associated with low academic achievement (Hart \& Risley, 1995). Given that Latino families continue to be overrepresented among America's poor (Hernandez, Denton, \& Macartney, 2008; Suárez-Orozco \& Páez, 2002), Latino language minority learners in the United States are thus particularly at risk for low levels of vocabulary and poor academic outcomes, even though bilingualism per se is not a risk factor (De Houwer, 1999; Petitto \& Holowka, 2002). These statistics have clear and immediate implications for US schools, particularly state-funded preschool programs and the nationally funded Early Head Start (EHS) and Head Start (HS) programs that promote school readiness for disadvantaged children. At

(C) Cambridge University Press 2011 0142-7164/11 \$15.00 
$34 \%$ of the total enrollment, low-income Latino children from Spanish-speaking homes comprise the largest and most rapidly growing segment of nonnative English speakers in EHS/HS (US Department of Health and Human Services, Administration for Children and Families, 2007), with trends suggesting that the number of Latinos in US schools will continue to increase in the coming years (Harwood, Leyendecker, Carlson, Asencio, \& Miller, 2002).

For children exposed to two or more languages, monitoring development in both languages is critical, because the child's vocabulary may be distributed across the two languages (Bedore, Peña, García, \& Cortez, 2005; Pearson, Fernández, \& Oller, 1995). Bilinguals rarely develop equal fluency in both (or multiple) languages, as they typically use their languages for different purposes, known as the complementary principle (see Grosjean, 1982, 1989, 2008). Yet, the dearth of tools designed to assess the vocabulary development of bilingual children under age 3 years and the lack of normative data on bilingual children's vocabulary attainment severely limit our understanding of vocabulary development for this growing population and present difficulties for practitioners in distinguishing between children developing normally and those who should be referred for further evaluation and intervention. The purpose of the study reported here was twofold. First, we investigated the utility and validity of two widely used measures of young monolingual children's vocabulary for use with low-income parents and their 24to 36-month-old Spanish-English bilingual children. Second, we considered issues in the interpretation of an integrated score derived from the two monolingual measures to index bilingual children's overall conceptual knowledge during this critical developmental period.

\section{ASSESSING BILINGUAL CHILDREN'S VOCABULARY DEVELOPMENT}

The possibility of language arrest or attrition associated with changing patterns of language input complicates the identification of what constitutes "typical" vocabulary development among bilingual children (e.g., for a review, see Anderson, 2004). Patterns of input associated with changes in family configuration, residence, and child care/preschool attendance are often reflected in quite dramatic changes in children's language dominance and vocabulary development over rather brief periods of time (see, e.g., the classic case study by Leopold in 1939). Furthermore, amount of exposure is itself an imperfect predictor of children's productive vocabulary growth in each language (Pearson, Fernández, Lewedeg, \& Oller, 1997).

Researchers thus underscore the need to assess bilingual children repeatedly over time in both languages and urge the development of measures specifically designed for, and normed on, bilingual children (Bedore \& Peña, 2008; Bedore et al., 2005; Caesar \& Kohler, 2007; Marchman \& Martinez-Sussmann, 2002; Pearson \& Fernández, 1994; Pearson, Fernández, \& Oller 1993). Nonetheless, to date, no such measure exists for children under age 36 months, making the adaptation of monolingual measures the only method currently available to assess the vocabulary of very young Spanish-English bilingual children. One such widely used tool is the MacArthur-Bates Communicative Development Inventory (CDI; Fenson et al., 2007) and its Spanish counterpart, the MacArthur Inventarios 
Mancilla-Martinez et al.: Bilingual children's vocabulary development

del Desarrollo de Habilidades Comunicativas (IDHC; Jackson-Maldonado et al., 2003), both designed to be completed by parents of children between the ages of 16 and 30 months (toddler forms). The Spanish IDHC is not a direct translation of the original English CDI as the Spanish version reflects relevant linguistic and cultural differences. However, both vocabulary forms incorporate the words young children typically learn first. As a result, there is considerable overlap (approximately $80 \%$ of the words) between the words on the English CDI and those on the analogous Spanish IDHC form. ${ }^{1}$ That the CDI and IDHC draw on parent knowledge of children's vocabulary use is especially useful for bilingual populations and for practitioners who are not themselves Spanish speakers.

The CDI/IDHC toddler forms follow a word checklist format that includes 680 semantically grouped words (e.g., household items, outside things, toys). ${ }^{2}$ Separate English CDI and Spanish IDHC scores provide valuable information on bilingual children's vocabulary development in each language, but separate scores may not be representative of bilingual children's overall vocabulary knowledge. For example, a Spanish-English bilingual child with identical scores on the English CDI and Spanish IDHC might be producing (a) exactly the same words in both languages, (b) completely unique words in each language, or (c) some of the same words in both languages and some unique words in each language. Without analyzing the English and Spanish scores in tandem, it is impossible to know whether a bilingual child knows the label for a word in only one or both languages and to determine the extent of overlap between their productive vocabularies in the two languages. Thus, an integrative analysis of the child's vocabulary production in English and in Spanish is needed to more accurately index and estimate their overall vocabulary knowledge. Pearson and colleagues have proposed adapting the English CDI and Spanish IDHC vocabulary measures so as to generate a "total conceptual vocabulary" (TCV) score to index and estimate bilingual children's vocabularies (Pearson et al., 1993, 1995; Pearson \& Fernandez, 1994). The TCV score is derived by simply summing the English and Spanish CDI/IDHC scores and then subtracting equivalent translation items (e.g., children do not receive double credit for knowing both table and mesa). The TCV score is intended to represent bilingual children's overall vocabulary knowledge in terms of known concepts. Thus, in addition to the standard English CDI and Spanish IDHC scores, a TCV score is examined in an attempt to more comprehensively index bilingual children's overall vocabulary knowledge.

Applying this methodology, Pearson and colleagues $(1993,1994)$ report that single language scores (e.g., separate CDI and IDHC raw scores) seemed to underestimate middle-income Spanish-English bilingual children's vocabulary knowledge, whereas the TCV score provided a more comprehensive picture of their overall vocabulary knowledge. Although bilingual children's English CDI and Spanish IDHC scores, considered separately, were lower than established monolingual norms, growth in their integrated TCV scores was similar to that of English monolingual children (Pearson et al., 1994). Pearson and colleagues (1995) also found that translation equivalents (lexical items reported for both languages) accounted for about $30 \%$ of the vocabulary of middle-income SpanishEnglish bilingual children, suggesting that although young bilingual children do know many words in both languages, much of their vocabulary is known in only 
one of the two languages. The authors conclude that vocabulary assessments, and eventually norms, for bilingual children should be based on their performance as measured with the help of a combined score of both English and Spanish rather than simply on scores on each language separately.

Marchman and Martinez-Sussmann (2002) subsequently examined the validity of using the CDI and IDHC with 24-month-old Spanish-English bilingual children. Their comparison of children's word production on the CDI and IDHC to analogous laboratory measures (i.e., real object-naming task and spontaneous language use) provide evidence for the validity of the CDI and IDHC as estimates of Spanish-English bilingual children's vocabulary knowledge, while underscoring the need to integrate bilingual children's vocabulary skills in both languages. Given the heterogeneity among bilingual children in the relative strength of language skills in their two languages, it is important to examine the utility of the $\mathrm{CDI} / \mathrm{IDHC}$ for subgroups of children with differing patterns of language dominance. Such an investigation would provide important groundwork preparatory to any effort to develop bilingual norms.

A key limitation of Marchman and Martinez-Sussmann's work (2002), like that of Pearson and colleagues (1993, 1995, 1994), was that their sample comprised primarily middle-class Spanish-speaking families, thereby providing little basis for generalizing the results to the lower income populations of English language learners predominantly served by toddler and preschool programs. To our knowledge, only one study (Boyce, Akers, Innocenti, Ortiz, \& Cook, 2008) has investigated the validity of the CDI and IDHC with the rapidly growing population of low-income Spanish-speaking children and families. Boyce and colleagues found moderate correlations (.42-.44) between the CDI and IDHC scores and analogous vocabulary measures (standardized picture-naming task and spontaneous language use) in English and Spanish and suggested caution should be exercised in using the CDI and IDHC with low-income Spanish-speaking families. As in the Marchman and Martinez-Sussmann study, children in the Boyce sample were about 24 months. Thus, there is a need for validation of the CDI and IDHC with older toddlers (and potentially preschoolers) from Spanish-English low-income families.

It is possible that, especially for bilingual children from low-income families, vocabulary development through age 36 months may still be captured by the CDI and IDHC toddler forms. Although there is an upward extension of the CDI in English (CDI-III), ${ }^{3}$ designed for use with children between ages 30 and 37 months, a Spanish equivalent is not currently available. If the CDI and IDHC were found to be appropriate and valid for slightly older bilingual toddlers/preschoolers, the use of the same form would allow for a developmental examination of growth in vocabulary knowledge across toddlerhood. This would provide practitioners with a tool for tracking vocabulary development over a period during which development ideally should be rapid and sustained. Such information could be an important addition to children's files as they transition from toddler to preschool settings and informative for speech language specialists to whom children are referred for further assessment. Thus, the first two questions addressed in this study have to do with the feasibility of using the CDI/IDHC for bilingual children through age 36 months and the validity of parent report in this age range for children from low-income families. 
Table 1. Raw English CDI and raw Spanish IDHC scores and corresponding percentile ranks for a 24-month-old female, taken from the CDI and IDHC technical manuals

\begin{tabular}{ccc}
\hline \hline $\begin{array}{c}\text { Total English } \\
\text { CDI Words }\end{array}$ & $\begin{array}{c}\text { Percentile } \\
\text { Rank }\end{array}$ & $\begin{array}{c}\text { Total Spanish } \\
\text { IDHC Words }\end{array}$ \\
\hline $653+$ & 99 & $665+$ \\
472 & 75 & 391 \\
346 & 50 & 229 \\
185 & 25 & 128 \\
92 & 10 & 58 \\
\hline \hline
\end{tabular}

Note: CDI, Communicative Development Inventory; IDHC, Inventarios del Desarrollo de Habilidades Comunicativas.

\section{THE NORMS CHALLENGE}

Assuming that parent report on bilingual children up to age 36 months from lowincome families is found to be valid, a key challenge remains how to interpret the individual language and conceptual vocabulary scores. As noted earlier, the CDI and IDHC were normed on English and Spanish monolingual children, respectively. Moreover, the two norming samples were not identical in demographic makeup. As a result, the mapping of raw scores to percentile ranks for English and Spanish are appreciably different. As Table 1 shows, a 24-month-old female producing 346 English words on the CDI falls at the 50th percentile, whereas the number of Spanish words represented at the 50th percentile on the IDHC is much lower (229 words; for details, see the CDI and IDHC technical manuals; Fenson et al., 2007; Jackson-Maldonado et al., 2003, respectively). When considering the integrated CDI/IDHC conceptual score (TCV), the situation is further complicated because of the lack of any norms associated with the score. The standard practice has been to apply the Spanish IDHC norms in interpreting the TCV score, based on the rationale that the Spanish IDHC norms reflect a wider range of socioeconomic levels than the English CDI norms (V.A. Marchman, personal communication, November 6, 2006). Given the low-income status of many Latino families in the United States (Suárez-Orozco \& Páez, 2002), the application of the Spanish IDHC norms to the integrated TCV score may be appropriate. However, considering the heterogeneity in vocabulary distribution across Spanish and English of bilingual children, it remains an open question whether it is actually more appropriate to apply the Spanish IDHC in interpreting the integrated TCV score for children with differing language dominance profiles. Thus, the third purpose of the current study is to illustrate the implications of using the English and Spanish norms for a sample of young Spanish-English bilingual children. This analysis extends the work of Pearson and colleagues (1993) to older Spanish-English bilingual children from low-income families. 
The present study addresses the above gaps in the literature about very young bilingual children from low-income families by asking the following questions:

1. Can the Spanish IDHC and English CDI forms be used to track the vocabulary development of bilingual children as old as 36 months with varying patterns of language dominance (e.g., Spanish-dominant, English-dominant, balanced)?

2. At ages 30 and 36 months, how do scores on the English CDI and Spanish IDHC compare to other concurrently administered direct standardized measures of Spanish-English bilingual children's vocabulary (e.g., Woodcock Language Proficiency Battery-Revised [WLPB-R] and Peabody Picture Vocabulary Test [PPVT])?

3. How do scores on measures of young Spanish speakers' vocabulary in English and in Spanish (i.e., English CDI score, Spanish IDHC score, and integrated conceptual vocabulary score) compare to established monolingual vocabulary norms? Further, does the proportion of children with differing language dominance profiles deemed "at risk" change depending on whether the Spanish or English norms are used to evaluate the integrated conceptual vocabulary score?

\section{METHOD}

\section{Participants}

The sample consisted of 79 Spanish-English bilingual mother-child dyads recruited from EHS and HS collaborating programs in northeastern Massachusetts. Like HS, EHS is a federally funded child development program for low-income families. EHS serves families with infants and toddlers up to the age of 3, whereas HS serves families with preschool-aged children. We report on 24- to 36-month Spanish-English children from bilingual or Spanish-speaking homes for whom parent report data were available in Spanish or both languages at one or more time points. As a group, we refer to children in the study as "Spanish-English bilinguals."

Parent interviews were conducted with $94 \%$ of the families $(n=74)$. Over $90 \%$ of the families identified themselves as Latino, with three identifying as White and three as mixed ethnicity. Only three children were reportedly born outside the United States, but the large majority of mothers (78\%) and fathers (83\%) were born in other countries, primarily the Dominican Republic and Puerto Rico. With one exception, mothers reported being a primary caregiver of the child, whereas $70 \%$ of fathers were described by mothers as being a primary caregiver. Twothirds of the mothers were employed at least part time ( $42 \%$ full time), and nearly $90 \%$ of fathers were employed ( $68 \%$ full time). The average household size was four people $(S D=1.60$, range $=2-12$ ), and the median annual family income was in the income bracket of $\$ 10,000-\$ 19,999$, well below the federal poverty guideline for a family of four (Federal Register, 2008). There was variability in parent education, with $16 \%$ of mothers reporting less than a high school education, and the remaining reporting a high school or postsecondary education. Somewhat lower levels of education were reported for fathers $(26 \%$ reportedly had less than a high school education and the remaining reportedly had a high school or 
postsecondary education), but this information was not known by mothers for nearly one-quarter of fathers $(22 \%)$. Sixty-eight percent of children had older siblings.

Families were recruited into the study when children were 24, 30, or 36 months. The staggered entry of study participants and the longitudinal design allowed for a larger sample size to address questions of utility and validity of the CDI/IDHC. Twenty-three children entered the study at age 24 months, 24 entered at age 30 months, and 32 at age 36 months. No significant differences in parental education, family income, and language exposure and use were noted between children who entered the study at different ages (see Appendix A).

\section{Participant recruitment}

Participants were recruited from collaborating EHS/HS sites where staff obtained verbal consent from parents for trained research assistants (RAs) to contact families and formally invite them into the study. RAs met with participating parents in person, gained formal consent, and conducted interviews and appropriate language assessments. All RAs were bilingual and the interviews and language assessments were available in both Spanish and English.

\section{Measures}

A parent interview provided relevant demographic and language use data. Measures of children's language development were obtained in both Spanish and English. The measures included parent reports and direct standardized assessments, both completed within a 1-month window to ensure that the two types of measures were temporally comparable.

Parent interview. Relevant demographic and language use information was obtained from parent interviews conducted at study entry (i.e., when the child was 24,30 , or 36 months). The interview was administered in person by an RA at the child's school or home, depending on parent preference, and took approximately 20 min to complete. Demographic information (summarized above) included child and parent ethnicity, child and parent place of birth, maternal and paternal years of education and employment status, and annual family income.

Parents were asked about the language(s) they wanted their child to speak when the child was older. All parents, except one, reported hoping that their child would grow up to be Spanish-English bilingual. The most common reasons for wanting children to be bilingual were to maintain contact with their Spanish-speaking family members and to afford more job opportunities. Rather than responding to a single global question about home language use, parents were asked to report on the language(s) they and other people in the household used when speaking to the child and on the language(s) the child used when speaking to them and to others in the household. As Table 2 shows, the reported input to most children by their parents was primarily Spanish. In contrast, the reported input to the child by other children in the home was primarily Spanish and English equally (in $45 \%$ of the families), or mostly/only English (in 41\%). In examining the reported 
Mancilla-Martinez et al.: Bilingual children's vocabulary development

Table 2. Percentage of language exposure to child and language use by child per parent report $(n=74)$

\begin{tabular}{lccc}
\hline \hline & $\begin{array}{c}\text { Only/Mostly } \\
\text { Spanish }\end{array}$ & $\begin{array}{c}\text { Equal Spanish } \\
\text { and English }\end{array}$ & $\begin{array}{c}\text { Mostly/Only } \\
\text { English }\end{array}$ \\
\hline $\begin{array}{l}\text { Language input to child } \\
\text { From mother }\end{array}$ & $63 \%$ & $29 \%$ & $8 \%$ \\
$\quad \begin{array}{l}\text { From father } \\
\text { From children in home }\end{array}$ & $73 \%$ & $14 \%$ & $13 \%$ \\
Language use by child & $14 \%$ & $45 \%$ & $41 \%$ \\
$\quad$ To parents & $41 \%$ & $23 \%$ & $36 \%$ \\
To children in home & $33 \%$ & $27 \%$ & $40 \%$ \\
To children outside home & $24 \%$ & $24 \%$ & $52 \%$ \\
\hline \hline
\end{tabular}

output by children, less than half of parents $(41 \%)$ reported that their children used mostly/only Spanish when speaking with their parents. With other children in the home, $40 \%$ used only/mostly English, and the percentage of children who used only/mostly English with children outside the home (e.g., at school) was even higher (52\%). Although all children were exposed to Spanish at home, 7\% $(n=5)$ heard minimal Spanish in the home, compared to 34\% $(n=25)$ who used minimal Spanish at home themselves. ${ }^{4}$ Despite this imbalance between input and children's own output, there was a significant correlation between maternal language input and child language output $(r=.45, p<.001)$ as well as between paternal language input and child language output $(r=.60, p<.001)$. We also explored the relationship between the combined maternal and paternal language input (for children with both parents in the home) and the child's own language output and, although lower in magnitude, the correlation remained positive and significant $(r=.32, p<.001)$.

Parent reports on child vocabulary. Parents (all mothers, with the exception of one father) completed the MacArthur-Bates CDI (Fenson et al., 2007) and its Spanish counterpart, the MacArthur IDHC (Jackson-Maldonado et al., 2003), long forms every 3 months beginning at study entry in the language(s) they used with their child and felt they could report on. They were urged to report only on the language(s) they heard their child use and felt confident they could report on. ${ }^{5}$ All 79 parents reported on their child's Spanish or Spanish and English vocabulary at least at one time point $(24,27,30,33$, or 36 months). Of these parents, 16 were only able to report on their child's Spanish vocabulary; their data are relevant only for the first two research questions having to do with the appropriateness of the IDHC through age 36 months and their validity for this population at ages 30 and 36 months. The remaining 63 parents were able to report on their children's English as well as Spanish vocabulary at one or more time points and are therefore included in analyses that address all three research questions. Twentyseven children contributed data at one time point, 11 contributed data at two time points, 18 contributed data at three time points, 4 data contributed at four time 
points, and 3 contributed data at five time points. Families who entered the study at child age 36 months $(n=32)$ only completed the CDI and/or IDHC once.

The CDI/IDHC were completed within a 1-month window (i.e., 2 weeks before to 2 weeks after the child turned 24, 27, 30,33, or 36 months). Parent literacy was not assumed; hence, RAs met with the parents in person either at the child's school or home, depending on parent preference, and gave parents the option of having the CDI/IDHC read aloud to them or of completing the forms on their own. In a few cases, parents were unable to complete the forms in the presence of the RA and thus requested to complete them on their own and return them to the child's school; RAs followed up with parents to ensure that the forms were returned to the child's teacher within the 1-month window.

On the CDI and IDHC, parents indicate whether their child spontaneously produces the listed words. ${ }^{6}$ The total number of words reported by parents provides an index of children's productive vocabulary knowledge in English and Spanish, respectively. Following Pearson's methodology (1993, 1994), three vocabulary scores were derived: (a) English CDI score, (b) Spanish IDHC score, and (c) TCV score (i.e., simple sum of the English CDI and Spanish IDHC scores minus translation equivalent items). The procedure for compositing the TCV score followed the CDI/IDHC concept-matching program developed by Marchman (1999). Marchman's mappings were used because Pearson's were done based on an earlier version of the CDI/IDHC forms and because more recent work has used this method of concept matching (e.g., Marchman \& Martinez-Sussmann, 2002; Marchman, Martinez-Sussmann, \& Dale, 2004). The developers of the CDI and IDHC report high internal consistency (Cronbach $\alpha$ s $=0.96$ and 0.94 for English and Spanish versions, respectively) and high stability (test-retest correlations of 0.95 and 0.81 for English and Spanish versions, respectively).

Direct standardized assessments. In addition to parent report measures, direct assessments of children's productive and receptive vocabulary knowledge were also conducted at child ages 30 and 36 months. The WLPB-R (Woodcock, 1991; Woodcock \& Muñoz-Sandoval, 1995) picture vocabulary subtest was used to assess children's productive vocabulary in English and in Spanish at child ages 30 and 36 months. Children named pictured objects that were ordered by increasing difficulty, with each response scored as correct or incorrect. The test-retest reliability was reported by the author as 0.75 for Spanish and 0.86 for English. The third edition of the PPVT ${ }^{7}$ (PPVT-III; Dunn \& Dunn, 1997) and the Test de Vocabulario en Imagenes Peabody (TVIP; Dunn, Padilla, Lugo, \& Dunn, 1986) were used to assess children's receptive vocabulary in English and in Spanish, respectively. Children were required to point to the picture that matched the target word provided by the examiner. The test-retest reliability reported by the authors was 0.80 for Spanish and 0.92 for English. The assessments were administered to children individually at school (or on a few occasions at home, when parents so requested) at ages 30 and 36 months in both English and Spanish. As with the procedure used to collect the $\mathrm{CDI} / \mathrm{IDHC}$, children were assessed within a 1-month window (i.e., 2 weeks before to 2 weeks after the child turned 30 or 36 months). Per the assessment manuals, RAs were instructed to provide children with ample opportunities to understand the testing instructions and to note on the 
testing booklet that the test could not be administered whenever a child did not understand the testing directions after multiple attempts to explain them.

\section{RESULTS}

\section{Child language dominance}

Given that we were interested in examining the utility of parent reports for children demonstrating different Spanish/English dominance profiles, we identified each child's language dominance based on parent reports of child vocabulary size using the IDHC and CDI scores. Language dominance using this approach could not be determined for the 16 children whose parents reported only on their Spanish vocabulary. For children who contributed data at more than one time point, language dominance was calculated separately at each time point to ensure that changes in children's language dominance from one time point to another were accounted for. We acknowledge that relying entirely on parent report may skew dominance in the direction of Spanish for those parents who hear their child use little English at home or whose own English receptive skills are relatively weak. However, doing so allows us to begin to explore patterns of English-Spanish vocabulary strength demonstrated by children who are often lumped together under the label "bilingual."

Because there are no research-based criteria for determining bilingual children's language dominance, we decided to calculate the ratio of Spanish to English words comprising the child's total reported vocabulary and assign language dominance as follows ${ }^{8}$ : children for whom the ratio was between 100:0 and 90:10 were considered virtual Spanish monolinguals, a ratio between 89:11 and 61:39 was classified as Spanish dominant, a ratio between 60:40 and 40:60 was classified as "balanced," a ratio between 39:61 and 11:89 was classified as English dominant, and a ratio between 10:90 and 0:100 was classified as virtual English monolingual. Table 3 displays children's language dominance at each age (24-36 months).

Research Question 1: Can the Spanish IDHC and English CDI forms be used to track the vocabulary development of bilingual children as old as 36 months with varying patterns of language dominance (e.g., Spanish dominant, English dominant, balanced)?

The MacArthur-Bates CDI toddler forms are designed for use with children through age 30 months. However, given that converging evidence indicates that low-income children generally have more depressed vocabularies than their middle-income peers (e.g., Hart \& Risley, 1995; Snow et al., 1998), coupled with findings that nonnative English-speaking children tend to have smaller vocabularies than monolingual English speakers (e.g., for a review, see Lesaux, Koda, Seigel, \& Shanahan, 2006), we hypothesized that use of the IDHC/CDI would be appropriate with EHS/HS Spanish-English-speaking children through age 36 months. We therefore asked parents to report on their child's vocabulary at child age 33 and 36 months.

We address here the possible ceiling effects separately for the subgroups of children with differing language dominance classification. Specifically, IDHC 
Mancilla-Martinez et al.: Bilingual children's vocabulary development

Table 3. Child language dominance from age 24 to 36 months, based on CDI and IDHC scores

\begin{tabular}{cccccc}
\hline \hline & \multicolumn{5}{c}{ Language Dominance Classification } \\
\cline { 2 - 6 } Child Age & $\begin{array}{c}\text { Virtual } \\
\text { Spanish } \\
\text { Monolingual }\end{array}$ & $\begin{array}{c}\text { Spanish } \\
\text { Dominant }\end{array}$ & Balanced & $\begin{array}{c}\text { English } \\
\text { Dominant }\end{array}$ & $\begin{array}{c}\text { Virtual } \\
\text { English } \\
\text { Monolingual }\end{array}$ \\
\hline 24 months $(n=16)$ & 0 & 4 & 5 & 4 & 3 \\
27 months $(n=16)$ & 1 & 5 & 4 & 3 & 3 \\
30 months $(n=29)$ & 0 & 9 & 5 & 11 & 4 \\
33 months $(n=19)$ & 1 & 4 & 6 & 5 & 3 \\
36 months $(n=45)$ & 0 & 6 & 15 & 14 & 10 \\
\hline \hline
\end{tabular}

Note: At 24 months, 2 parents provided only a Spanish report and 1 parent only an English report; at 27 months, 1 parent provided only a Spanish report; at 30 months, 4 parents provided only a Spanish report and 2 only an English report; at 33 months, 7 parents provided only a Spanish report and 2 only an English report; at 36 months, 17 parents provided only a Spanish report and 1 only an English report. CDI, Communicative Development Inventory; IDHC, Inventarios del Desarrollo de Habilidades Comunicativas.

scores are reported separately for children displaying a Spanish-dominant profile, virtual Spanish-monolingual profile, or for children whose parents only reported in Spanish and then for children displaying a balanced profile. Similarly, CDI scores are reported separately for children displaying an English-dominant profile, a virtual English monolingual profile, or for children whose parents only reported in English and then for children displaying a balanced profile. As Table 4 shows, there were no ceiling effects on the IDHC or CDI for any of these languagedominance subgroups at ages 33 or 36 months. In addition, the IDHC and CDI parent reports were found to capture much variability at child ages 33 and 36 months. This suggests that the use of the IDHC and CDI is appropriate for this group of Spanish-English bilingual children through at least age 36 months.

Research Question 2: At ages 30 and 36 months, how do scores on the English CDI and Spanish IDHC compare to other concurrently administered direct standardized measures of Spanish-English bilingual children's vocabulary (e.g., WLPB-R and PPVT)?

The validity of the CDI/IDHC with low-income families has been a point of contention (e.g., Pan, Rowe, Spier, \& Tamis-LeMonda, 2004; Roberts, Burchinal, \& Durham, 1999), particularly when parents complete reports about their children's production in a language other than the primary home language (Boyce et al., 2008). Further, these studies have focused on children younger than 30 months. Thus, it was of interest to investigate how closely associated reports of low-income parents on their Spanish-English bilingual children's vocabulary were with standardized direct assessment measures at child ages 30 and 36 months. As with previous validation studies of the $\mathrm{CDI} / \mathrm{IDHC}$, concurrent validity was assessed using correlation analyses. The CDI and IDHC scores were correlated with 
Table 4. Spanish IDHC and English CDI scores at child ages of 33 and 36 months for Spanish-dominant, English-dominant, and balanced children

\begin{tabular}{|c|c|c|c|c|}
\hline & Mean & $S D$ & Min. & Max. \\
\hline \multicolumn{5}{|c|}{ Spanish-dominant children IDHC scores } \\
\hline 33 months $(n=12)$ & 410.00 & 219.67 & 7 & 659 \\
\hline 36 months $(n=23)$ & 395.96 & 156.56 & 16 & 640 \\
\hline \multicolumn{5}{|c|}{ English-dominant children CDI scores } \\
\hline 33 months $(n=10)$ & 362.10 & 158.60 & 112 & 634 \\
\hline 36 months $(n=25)$ & 409.04 & 134.96 & 158 & 667 \\
\hline \multicolumn{5}{|c|}{ Balanced bilingual children IDHC scores } \\
\hline 33 months $(n=6)$ & 329.67 & 122.58 & 132 & 506 \\
\hline 36 months $(n=15)$ & 334.60 & 195.85 & 20 & 599 \\
\hline \multicolumn{5}{|c|}{ Balanced bilingual children CDI scores } \\
\hline 33 months $(n=6)$ & 288.50 & 115.05 & 156 & 496 \\
\hline 36 months $(n=15)$ & 328.87 & 198.01 & 18 & 620 \\
\hline
\end{tabular}

Note: The Spanish-dominant sample includes children displaying only a Spanish-dominant or virtual Spanish monolingual profile; the English-dominant sample includes children displaying only an English-dominant or virtual English monolingual profile; the balanced bilingual sample includes children displaying only a Spanish-English "balanced" profile; maximum score on IDHC and $\mathrm{CDI}=680$ words. IDHC, Inventarios del Desarrollo de Habilidades Comunicativas; CDI, Communicative Development Inventory.

Table 5. Correlations between the CDI and IDHC at child ages of 30 and 36 months to expressive and receptive measures of vocabulary

\begin{tabular}{llllll}
\hline \hline & \multicolumn{2}{c}{30 Months } & & \multicolumn{2}{c}{36 Months } \\
\cline { 2 - 3 } \cline { 5 - 6 } & \begin{tabular}{c} 
CDI \\
\cline { 5 - 6 }
\end{tabular} & $\begin{array}{c}\text { IDHC } \\
(n=27)\end{array}$ & & $\begin{array}{c}\text { CDI } \\
(n=44)\end{array}$ & $\begin{array}{c}\text { IDHC } \\
(n=54)\end{array}$ \\
\hline WLPB-R & $.51 * *$ & $.66^{* * *}$ & & $.38^{*}$ & $.60^{* * *}$ \\
PPVT/TVIP & .17 & $.44 *$ & & $.31^{*}$ & $.36^{* *}$ \\
\hline \hline
\end{tabular}

Note: CDI, Communicative Development Inventory; IDHC, Inventarios del Desarrollo de Habilidades Comunicativas; WLPB-R, Woodcock Language Proficiency Battery-Revised; PPVT, Peabody Picture Vocabulary Test; TVIP, Test de Vocabulario en Imagenes Peabody.

$* p<.05 . * * p<.01 . * * * p<.001$.

criterion measures of children's productive and receptive vocabulary, the WLPB-R in English and Spanish and the PPVT/TVIP, respectively.

As shown in Table 5, there were low-moderate to high-moderate positive and significant correlations between the CDI and IDHC and children's productive vocabulary (WLPB-R) at child age 30 and 36 months. Similarly, except in English at child age 30 months, the CDI and IDHC was positively correlated with children's 
receptive vocabulary (PPVT/TVIP). Because the CDI/IDHC toddler forms were intended to measure young children's productive vocabulary, the stronger association between the CDI/IDHC and the WLPB-R, compared to the association between the CDI/IDHC and the PPVT/TVIP, was anticipated. To confirm that the CDI/IDHC is actually a measure of children's productive vocabulary, we also examined the multiple correlation between the CDI/IDHC and the criterion vocabulary measures. When the WLPB-R was entered together with the PPVT/TVIP, the PPVT/TVIP did not contribute uniquely in explaining variation in the CDI/IDHC, indicating that the WLPB-R captures all of the variation that is explained by the PPVT/TVIP. This indicated that our low-income sample of parents was able to make a distinction between words they heard children say and words that children understand, thus providing some support for the validity of the CDI/IDHC as a measure of productive vocabulary for low-income Spanish-English bilingual children, even at age 36 months which is beyond the age for which these reports were designed. Furthermore, the magnitude of the correlations was stronger for Spanish than for English, at both 30 and 36 months, suggesting that parents do a better job of reporting in the home language (Spanish) than in the second language (English).

Research Question 3: How do scores on measures of young Spanish speakers' vocabulary in English and in Spanish (i.e., English CDI score, Spanish IDHC score, and integrated conceptual vocabulary score) compare to established monolingual vocabulary norms? Further, does the proportion of children with differing language dominance profiles deemed "at risk" change depending on whether the Spanish or English norms are used to evaluate the integrated conceptual vocabulary score?

A comparison of the CDI, IDHC, and the integrated CDI/IDHC scores (i.e., TCV) to established monolingual CDI and IDHC norms was conducted to investigate the utility of examining the integrated vocabulary score (TCV) when indexing the vocabulary development of Spanish-English bilingual children. However, we first explored whether children actually possess some unique words in each language, making the TCV score useful to consider. For 74 of the 79 children, TCV scores were higher at all time points than the single-language scores, indicating that some words were known uniquely in Spanish and some uniquely in English. Another way of thinking about the contribution of Spanish-English bilingual children's vocabulary in each language, based on the CDI and IDHC, is to compare the average percentage of their vocabulary that is uniquely in Spanish, uniquely in English, and that is known in both Spanish and English (i.e., overlap). Table 6 shows that, on average across all ages, $36 \%$ of children's vocabulary comprises words known in Spanish only, 38\% comprises words known in English only, and there is 26\% overlap in words known in both Spanish and English. Averaged across age, this degree of vocabulary overlap is only slightly lower than the 30\% reported by Pearson and colleagues (1995) for middle-income bilingual children. Visual inspection of percentages by age indicates a relatively stable pattern of English-only vocabulary (36\%-41\%), a decrease in percentage of Spanish-only vocabulary $(40 \%-30 \%)$, and an increase in the percentage of vocabulary overlap, that is, words know in both languages (21\%-29\%). 
Table 6. Average percentage of Spanish-only, English-only, and overlapping vocabulary by child age

\begin{tabular}{cccc}
\hline \hline $\begin{array}{c}\text { Age } \\
\text { (months) }\end{array}$ & $\begin{array}{c}\text { Spanish } \\
\text { Only }\end{array}$ & $\begin{array}{c}\text { English } \\
\text { Only }\end{array}$ & Overlap \\
\hline $24(n=13)$ & $40 \%$ & $39 \%$ & $21 \%$ \\
$27(n=12)$ & $40 \%$ & $37 \%$ & $24 \%$ \\
$30(n=25)$ & $36 \%$ & $39 \%$ & $25 \%$ \\
$33(n=15)$ & $32 \%$ & $36 \%$ & $32 \%$ \\
$36(n=35)$ & $30 \%$ & $41 \%$ & $29 \%$ \\
Across all ages & $36 \%$ & $38 \%$ & $26 \%$ \\
\hline \hline
\end{tabular}

Given that children possess some unique words in each language, as well as some overlapping vocabulary, we compared the single-language measures (CDI and IDHC) and the integrated TCV scores. Children with both a CDI and IDHC score at any one time point (i.e., 24, 27, 30,33, or 36 months) were included in this analysis. However, children displaying a virtual Spanish monolingual profile $(n=$ 2 ) or an English monolingual profile $(n=10)$ were excluded from this analysis as their English or Spanish vocabulary was essentially zero and thus their English or Spanish vocabulary would minimally, if at all, contribute to their integrated TCV score. Thus, a total of 51 children were included in this analysis, with some children (i.e., those for whom longitudinal data were collected) represented at two or more time points $(n=31)$. As has been common practice to date, the Spanish norms were used to interpret the TCV scores. In addition, and unlike previous work, the English norms were also used to interpret the TCV scores. For this comparison, the percentiles that correspond to the CDI and IDHC norms were converted to standard scores. This conversion was made because standard scores, unlike percentiles, are on an equal-interval scale and can meaningfully be averaged for comparative purposes. For example, a CDI or IDHC percentile score of 50 was converted to a standard score of 100 (see Appendix B for explication of the conversion process). As Figure 1 illustrates, use of only the single-language measures (i.e., English CDI or Spanish IDHC) resulted in a larger number of Spanish-English bilingual children falling one or more SD below the mean across all ages (24-36 months). Specifically, across all ages, 13 children fell one or more SD below the mean in English. Similarly, in Spanish, 10 children fell one or more SD below the mean. By taking an integrative account of the two languages using the TCV scores and applying the Spanish IDHC norms, across all ages only six children fell $\geq 1 S D$ below the mean. We next examined whether the number of "at-risk" children would change if the English rather than the Spanish norms were applied to TCV scores. By applying the English CDI norms to the TCV scores, an average of 8 children fell $\geq 1 S D$ below the mean. In other words, across all ages except at 33 months, more children fell $\geq 1 S D$ below the mean when the English norms were applied to the TCV score than when the Spanish norms were used to interpret this score. The average standard scores when the Spanish norms were applied to the TCV scores were significantly higher $(p<.001)$ across all 
Mancilla-Martinez et al.: Bilingual children's vocabulary development

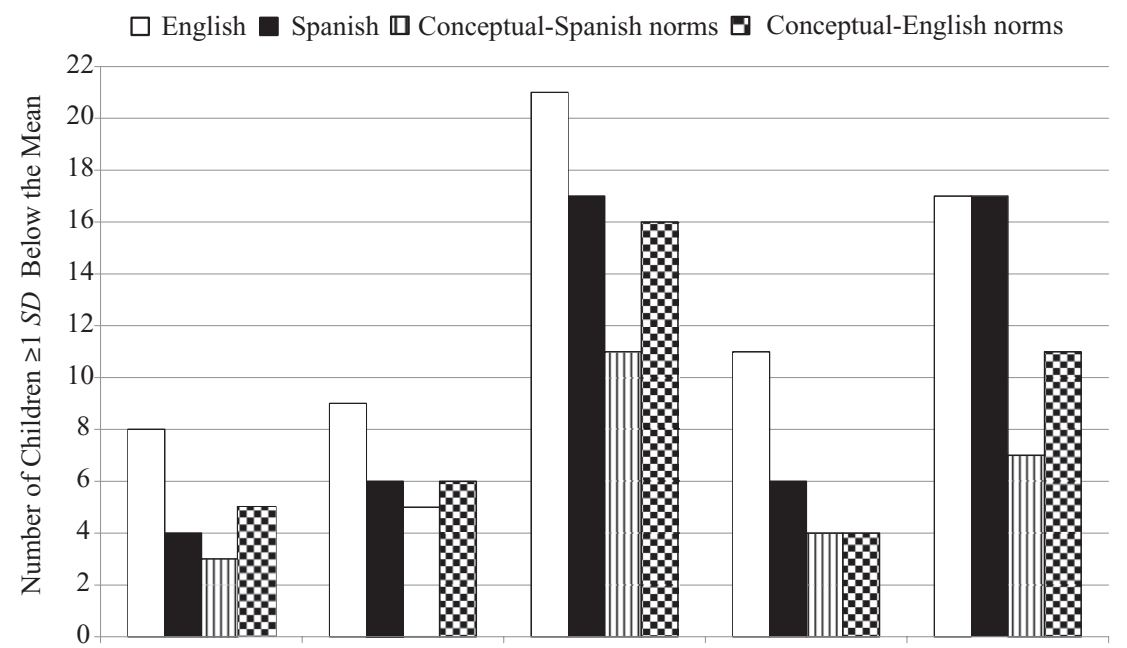

24months $(n=13) 27$ months $(n=12) 30$ months $(n=25) 33$ months $(n=15) 36$ months $(n=35)$

Figure 1. The number of children who fall $\geq 1 S D$ below the mean on the English Communicative Development Inventory (CDI), Spanish Inventarios del Desarrollo de Habilidades Comunicativas (IDHC), and total conceptual vocabulary (integrated CDI and IDHC) score using the Spanish and English norms from age 24 to 36 months.

ages compared to when the English norms were applied to interpret this score (see Table 7). Use of the English norms to interpret the TCV scores actually resulted in children looking $0.5 S D$ worse on average.

Finally, considering the variability in bilingual children's patterns of language dominance, we examined shifts in TCV scores in standard score units for subgroups of children with differing language dominance profiles when the English versus Spanish norms are used. Figure 2 shows the difference in TCV scores in standard score units (Spanish TCV norms minus English TCV norms). The height of the bars represents the difference in favor of applying the Spanish norms to the TCV scores. For example, for English-dominant children at age 30 months, use of the Spanish norms to interpret the TCV scores results in an average standard score that is two-thirds of a standard deviation higher than if the English norms had been used to interpret the TCV scores. As the figure shows, use of the Spanish norms resulted in higher Spanish TCV scores for all language-dominance subgroups at all ages; except for "balanced" children at age $27(n=4)$ and 30 months $(n=$ $5)$, the difference in standard scores were all statistically significant $(p<.05)$. For the Spanish-dominant children, application of the Spanish norms results in an advantage that increases for older children. For English-dominant children, use of the English CDI norms results in a smaller, but nonetheless significant, disadvantage that decreases with age from child age 27 to 30 months. Finally, for the balanced children, the difference in standard scores is small, at about two-fifths of a standard deviation and does not change substantially for children of different ages. Thus, particularly for children who were not "balanced" bilinguals, use of 
Table 7. Average TCV SS by age (24-36 months) when Spanish IDHC versus English CDI norms are applied to the TCV score

\begin{tabular}{|c|c|c|c|}
\hline & Mean & $S D$ & Difference in TCV SS \\
\hline \multicolumn{4}{|l|}{24 months $(n=13)$} \\
\hline TCV_Spanish norms & 92.62 & 13.59 & \\
\hline TCV_English norms & 86.85 & 13.21 & \\
\hline \multicolumn{4}{|l|}{27 months $(n=12)$} \\
\hline TCV_Spanish norms & 91.75 & 13.11 & \\
\hline \multirow[t]{2}{*}{ TCV_English norms } & 83.83 & 16.52 & \\
\hline & \multicolumn{3}{|c|}{30 months $(n=25)$} \\
\hline TCV_Spanish norms & 88.96 & 16.89 & \\
\hline \multirow[t]{2}{*}{ TCV_English norms } & 80.44 & 18.73 & \\
\hline & & & $8.52(t=6.41, p<.001)$ \\
\hline \multicolumn{4}{|l|}{33 months $(n=15)$} \\
\hline TCV_Spanish norms & 100.00 & 14.66 & \\
\hline TCV_English norms & 91.43 & 16.36 & \\
\hline \multicolumn{4}{|l|}{36 months $(n=35)$} \\
\hline TCV_Spanish norms & 100.40 & 17.85 & \\
\hline \multirow[t]{2}{*}{ TCV_English norms } & 93.06 & 20.44 & \\
\hline & & & $7.34(t=8.13, p<.001)$ \\
\hline
\end{tabular}

Note: TCV SS, total conceptual vocabulary standard scores; IDHC, Inventarios del Desarrollo de Habilidades Comunicativas; CDI, Communicative Development Inventory.

the Spanish versus English norms in interpreting TCV scores affected standard scores.

\section{DISCUSSION}

The results of this study extend our understanding of vocabulary development among young Spanish-English bilingual children from low-income families. The MacArthur-Bates CDI (Fenson et al., 2007) and the MacArthur IDHC (JacksonMaldonado et al., 2003) were used to measure children's vocabulary development in English and Spanish. Our results indicate that the CDI and IDHC can be used with this population at least through age 36 months, which is beyond the age range for which the CDI and IDHC were originally designed. In addition, lowincome Spanish-speaking parents were found to be able to make a distinction between their children's productive vocabularies versus receptive vocabularies in both Spanish and English. Finally, in line with previous work (Marchman \& Martinez-Sussmann, 2002; Pearson et al., 1993, 1994), our results confirmed the value of the integrated $\mathrm{CDI} / \mathrm{IDHC}$ score (i.e., TCV) as a measure of young bilingual children's overall vocabulary knowledge. However, given the lack of 


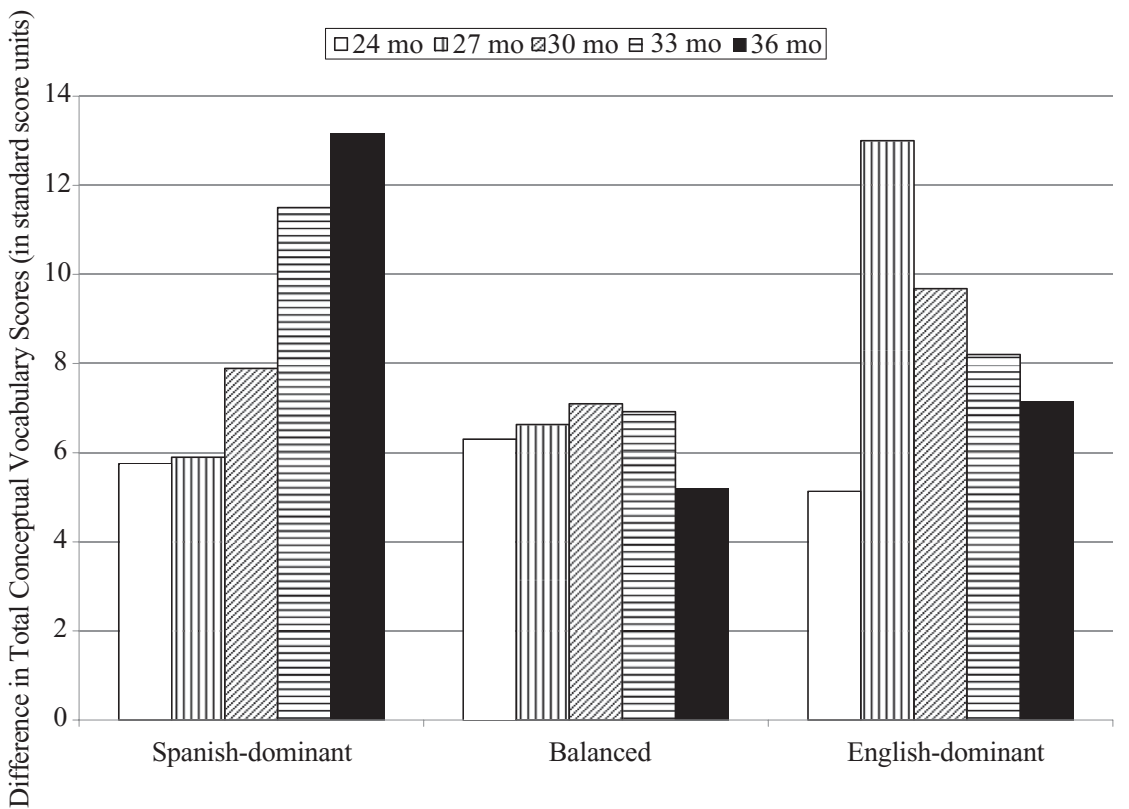

Figure 2. The average difference in Spanish-English bilingual children's total conceptual vocabulary scores (TCV) in standard score units (i.e., TCV_Spanish Norms minus TCV_English Norms) by language dominance from age 24 to 36 months. Sample sizes are as follows: Spanishdominant children 24 months $(n=4), 27$ months $(n=5), 30$ months $(n=9), 33$ months $(n=4)$, 36 months $(n=6)$; balanced children 24 months $(n=5), 27$ months $(n=4), 30$ months $(n=5)$, 33 months $(n=6), 36$ months $(n=15)$; English-dominant children 24 months $(n=4), 27$ months $(n=3), 30$ months $(n=11), 33$ months $(n=5), 36$ months $(n=14)$.

norms associated with the integrated TCV score, the complexity of determining how best to interpret this score was underscored, extending previous work in this area. Each of these findings and their theoretical and practical implications are discussed below.

\section{Language exposure and use}

Although not originally a primary focus of the study, it became clear that program designation of children's home environment as Spanish-speaking or bilingual encompasses wide variability in children's exposure to and use of their two languages. Whereas the large majority of children heard mostly or only Spanish from at least one parent, some heard mostly or only English. Furthermore, language input from other children in the family was much more frequently primarily English. Parents also reported that the children studied were themselves less likely to use mostly or only Spanish, even when addressing adults in the home. Thus, simply asking parents to identify "the home language(s)" is insufficient if we are to understand patterns of exposure and use that can be expected to relate to children's vocabulary 
Mancilla-Martinez et al.: Bilingual children's vocabulary development

growth. Rather, such inquiry should include language input from other children in the family as well as parents, and include information about the target child's own language use with family members. If the focus is on productive vocabulary, as it is with the CDI and IDHC words and sentences, then parent reporters can only report on what they hear children themselves say.

\section{Utility and validity of CDI/IDHC toddler forms for beyond age 30 months}

Our hypothesis that Spanish-English bilingual children aged 33 and 36 months from low-income families would not reach ceiling on the CDI and/or IDHC toddler forms was confirmed. The average CDI raw score for children aged 33 and 36 months in this study was 347 words (out of a possible 680). The average IDHC score was slightly higher at 368 words (out of a possible 680). Clearly, children's vocabulary achievement based on the CDI/IDHC does not capture the totality of their lexical knowledge because, by design, vocabulary assessments necessarily incorporate only a subset of words. Nonetheless, these results indicate that the English and Spanish toddler forms may be useful for tracking vocabulary development of children from low-income Spanish-speaking or bilingual families at least through entry to preschool.

We next addressed the validity of the CDI and IDHC for this population. Whereas some previous work (e.g., Feldman et al., 2000; Pearson et al., 1997; Rescorla \& Achenbach, 2002) has raised concern about the potential underreporting of children's vocabulary by minority parents, only one other study to date (Boyce et al., 2008) has investigated the validity of the CDI and IDHC specifically with low-income Spanish-speaking parents, and this was with 24-month-olds. We found positive and significant associations between parent report and direct assessments of children's vocabulary at ages 30 and 36 months. The magnitude of the correlation coefficients for the Spanish reports ranged from moderate to highmoderate, similar to those reported by Thal, Jackson-Maldonado, and Acosta (2000) for 20-month-old children from middle- to upper-middle income families, but lower than those reported by Marchman and Martinez-Sussman (2002) for 24-month-old children from middle-income families. Although the validity coefficients for English are lower than those reported for middle-income families (Fenson et al., 2007), the stronger correlations of the Spanish and English reports with assessments of children's productive rather than receptive vocabularies provide some support for the validity of low-income parent reports. In other words, our results suggest that parents were discriminating between words their children say versus the words they understand. Further, the stronger validity coefficients for the Spanish compared to the English reports suggest that parents are better at providing information about their children's primary than secondary language. However, a more detailed examination with the same bilingual families and a sample of low-income monolingual families indicated that parent reports about children's English vocabularies were significantly associated with WLPB-R scores even after controlling for the effects of home language status and child SpanishEnglish use (Vagh, Pan, \& Mancilla-Martinez, 2009). In addition, the pattern of differences noted for the parent CDI reports because of home language status and child Spanish-English use paralleled the differences noted for the WLPB-R scores, lending additional credibility for the parent English reports. Of course, the 
use of direct assessments as criterion measures to validate parent reports is less than ideal, as the WLPB-R assessments are not context and task independent and are subject to the child's ability to follow instructions. In light of the limitations, we can conclude that these results provide support for the use of the CDI and IDHC with low-income Spanish and Spanish-English parents beyond the age range for which the forms were originally designed.

The CDI and IDHC can therefore serve as a valuable nonintrusive tool that toddler/preschool staff can use to index the productive vocabulary development of young Spanish-English bilingual children, even when the staff is not SpanishEnglish bilingual, as the parents would serve as the reporters. It is impractical to assess very young children with direct assessments such as the WLPB-R and PPVT/TVIP repeatedly over time as repeated assessments may familiarize children with the test items and more readily lead to practice effects. Further, such testing must be conducted by trained staff and is subject to the ability of children to follow instructions. The CDI and IDHC, in contrast, can be a cost-effective, context- and task-independent, valid, and practical alternative means of tracking children's vocabulary growth and identifying children whose growth in both languages may be slower than expected. As with all measures, however, there are limitations to the use of the CDI and IDHC. In particular, the long forms used in the present study may be burdensome for parents to complete in two languages. Thus, further research is needed to assess the validity of the CDI/IDHC short forms (comprising 100 words each) for this population.

\section{The norms conundrum}

As noted earlier, the CDI and IDHC norming samples were not identical in demographic makeup (for details, see the CDI and IDHC technical manuals; Fenson et al., 2007; Jackson-Maldonado et al., 2003, respectively), which leads to two potential problems. The first is the risk of treating the bilingual child as a "monolingual" speaker of Spanish or of English. Previous research with Spanish-English bilingual children from middle-income homes (Pearson et al., 1993, 1994; Marchman \& Martinez-Sussmann, 2002) suggests that single language measures of vocabulary fall short of capturing the totality of bilingual children's vocabulary knowledge and tend to make the bilingual child seem more vocabulary challenged than when integrated CDI/IDHC scores (i.e., TCV) are considered. The current study confirmed the value of integrated scores for assessing low-income Spanish-English bilingual children's vocabulary. With very few exceptions, children's TCV raw scores were higher than their single-language scores. Translation equivalent items (i.e., words children were reported to know in both languages) actually accounted for $21 \%$ to $32 \%$ of bilingual children's vocabulary. This indicates that, although up to one-third of their vocabulary is known in both Spanish and English, much of low-income bilingual children's vocabulary comprises words known uniquely in Spanish or English. Without analyzing the CDI and IDHC scores in tandem, the extent to which bilingual children concentrate vocabulary growth in one language, or are learning lexical labels for the same concept in both languages, remains unknown. Thus, any single-language measure is likely to fail to capture the totality of bilingual children's conceptual understanding. A clear practical implication is 
thus that preschool teachers cannot assume that the language abilities of SpanishEnglish bilingual children are comparable. Perhaps of more importance, simply because a Spanish-English bilingual child does not have the label for a word in one language does not mean the child does not have the conceptual knowledge. It is a challenge for early childhood educators to determine whether a bilingual child is "at risk" for language delays or whether they are simply still in the process of developing their language abilities in English and/or Spanish. Failure to move beyond use of single language scores to measure bilingual children's vocabulary may lead to overidentification of language delays (Bedore et al., 2005). In contrast, routinely assuming that the bilingual child probably knows the concept and lexical item in their home language may lead to language delay underidentification.

However, use of the TCV score leads to the second problem, lack of norms associated with the score. As previously noted, the Spanish IDHC norms have been applied in interpreting the TCV integrated score, based on the rationale that the Spanish IDHC norms have a wider range of socioeconomic levels represented than the English CDI norms (V. A. Marchman, personal communication, November 6, 2006). However, considering the heterogeneity demonstrated here in Spanish and English vocabulary levels of children exposed to both Spanish and English, as well as the wide variation in home language environments, it is possible that the upward shift in standard scores based on TCV scores when compared to the IDHC norms is spurious, particularly for children demonstrating an English-dominant profile. Our comparison of the use of Spanish versus English norms to interpret the TCV scores did show that the TCV scores are significantly higher when interpreted with the Spanish norms. Further, an examination of standard scores for subgroups of children with differing language dominance profiles revealed that for all children, but in particular for children with either a Spanish- or English-dominant profile, there are notable shifts in standard scores. These results underscore the need for more research to establish appropriate benchmarks, ideally the development of bilingual norms for children with different language profiles (see Mueller Gathercole, Thomas, \& Hughes, 2008), to help ensure that young bilingual children are not over- or underreferred for special services.

\section{Directions for future research}

In the present study, all children were exposed to English by age 3, but future research that specifically inquires about the age at which children's exposure to the nonnative language began is merited. Specifically, such information would provide additional insight when interpreting bilingual children's vocabulary achievement relative to monolingual norms (e.g., Grosjean, 1989). Further, because nearly all of the child assessments were conducted at the child's school (in this case EHS/HS settings), the extent to which there might have been context effects (i.e., more English, more Spanish, or more bilingual use being activated as a function of setting) could not be evaluated. However, some work suggests that the setting can play a role in priming bilinguals toward a more monolingual or bilingual language mode (for details, see Grosjean, 1982, 1989, 2008), underscoring the need for further research in this area. In addition, report by a single familiar adult may underestimate children's vocabulary knowledge, for either monolingual or 
bilingual childen (De Houwer, Bornstein, \& De Coster, 2006; De Houwer, Bornstein, \& Leach, 2005; Marchman \& Martinez-Sussmann, 2002). For bilingual children, teachers may be especially valuable as additional reporters of children's nonnative vocabulary knowledge. However, in a study with the same sample of bilingual children and a sample of monolingual children we found that although the unique teacher contributions to parent reports were significantly greater for children from bilingual than monolingual families, we did not find the combined parent-teacher reports to be valid estimations of children's English productive vocabularies (Vagh et al., 2009). It is possible that the long forms, comprising 680 items and administered at periodic intervals, posed a sizeable burden on teachers and that use of the CDI short forms for toddlers, comprising only 100 items, might be more desirable, particularly for repeated measurements. We are currently exploring this possibility.

Finally, a potential limitation to the generalizability of the results of this study to children from other Spanish-English bilingual low-income families is the relatively high level of parental education among participating families. However, educational attainment among Latino immigrants continues to improve (Pew Hispanic Center, 2006), at the same time that family incomes continue to lag behind those of native-born adults (Hernandez et al., 2008; Suárez-Orozco \& Páez, 2002). Thus, families in the current study are not demographically atypical of Latino families served by many EHS, HS, and state-funded programs in the United States. A fuller picture of the language development of young children in such families is a pressing need for educators.

\section{APPENDIX A}

Sample means (standard deviations) and statistics for testing differences in selected background variables between children who entered the study at 24 months $(n=23), 30$ months $(n=24)$, and 36 months $(n=32)$

\begin{tabular}{|c|c|c|c|c|c|}
\hline \multirow[b]{2}{*}{ Variable } & \multicolumn{3}{|c|}{ Study Entry } & \multirow[b]{2}{*}{$F$} & \multirow[b]{2}{*}{$p$} \\
\hline & 24 Months & 30 Months & 36 Months & & \\
\hline \multicolumn{6}{|c|}{ Education (years) } \\
\hline Mother & $12.86(3.59)$ & $13.13(1.91)$ & $12.19(2.97)$ & & \\
\hline Father & $10.82(3.64)$ & $11.27(3.45)$ & $12.00(5.41)$ & 0.35 & .71 \\
\hline Income $^{a}$ & $2.63(1.59)$ & $2.33(1.09)$ & $2.72(1.79)$ & 0.43 & .65 \\
\hline \multicolumn{6}{|c|}{ Language use to child ${ }^{b}$} \\
\hline Mother & $2.64(1.59)$ & $3.25(1.70)$ & $2.22(1.34)$ & 2.84 & .07 \\
\hline Father & $2.39(1.42)$ & $2.29(1.71)$ & $1.78(1.09)$ & 1.13 & .32 \\
\hline \multicolumn{6}{|c|}{ Child's language use $^{b}$} \\
\hline To mother & $2.77(1.27)$ & $3.00(1.53)$ & $3.07(1.27)$ & 0.31 & .73 \\
\hline To father & $2.68(1.38)$ & $2.94(1.61)$ & $2.61(1.27)$ & 0.27 & .76 \\
\hline
\end{tabular}

Note: Parent interview data were not available for five children.

${ }^{a} 1=$ income bracket under $\$ 10,000,2=$ income bracket between $\$ 10,000$ and $\$ 19,999,3=$ income bracket between $\$ 20,000$ and $\$ 29,999$.

${ }^{b} 1=$ only/mostly Spanish, 2 = English and Spanish, $3=$ only/mostly English . 
Mancilla-Martinez et al.: Bilingual children's vocabulary development

\section{APPENDIX B: STANDARD SCORES CONVERSION PROCESS}

Unlike percentile scores, standard scores are on an equal-interval scale. This means that the difference between any two consecutive standard scores is the same across the distribution of scores thus enabling the estimation of averages. In contrast, the difference between two consecutive percentile scores varies as a function of its placement on the score distribution. For example, a percentile score of 20 is closer to a percentile score of 30 than it is to a percentile score of 10 . Therefore, percentile scores cannot be averaged. Because we were interested in averaging students' normative scores on the CDI and IDHC, we simply mapped the percentile scores (the only normative score provided by the CDI and IDHC) to their corresponding standard scores. In other words, each percentile score was assigned the corresponding standard score. For example, a percentile score of 16 corresponds to a standard score of 85 , a percentile score of 50 corresponds to a standard score of 100 , and a percentile score of 84 corresponds to a standard score of 115 . We did not use $z$ scores because the CDI and IDHC only provide the means and standard deviations for both sexes combined and there are notable differences by gender. For example, a 24-month-old female producing 346 words falls at the 50th percentile whereas a 24-month-old male only needs to produce 252 words to fall at the 50th percentile. This would have left the option of using our sample mean and standard deviation, but we wanted to ensure that our sample's scores could be compared to established CDI and IDHC norms. Thus, use of the CDI and IDHC percentiles, and subsequently the mapping of percentiles onto their corresponding standard scores, was necessary.

\section{ACKNOWLEDGMENTS}

This research was supported by Administration for Children, Youth and Families/Head Start Bureau Grant 90YF0049 (to B.A.P.). The authors express their appreciation to participating families. The writing of this article was partially supported by the Dean's Summer Research Fellowship, Harvard Graduate School of Education (to J.M.-M.).

\section{NOTES}

1. There are established guidelines for the adaptation of the CDIs in other languages (for details, see Dale, Fenson, \& Thal, 1993) to ensure comparability of the forms to the original CDI.

2. Short forms, comprising 100 words, are also available.

3. There is only a limited amount of norming and validation data for the CDI-III.

4. This was defined as less Spanish than English with all family members in the home.

5. Among the families reporting in both languages at one or more times points, three families reported in only English at one time point despite reporting in both at other times points and six families reported in only Spanish at one time point despite reporting on both at other times. When this occurred, the single language data was only used to address Research Questions 1 and 2, having to do with the appropriateness of the $\mathrm{CDI} / \mathrm{IDHC}$ and their validity.

6. Given the lack of research-based criteria to determine whether there are threshold levels of proficiency in a language to deem a reporter an "adequate" reporter, parents in this study were allowed to decide themselves whether they could or could not report on their child's English vocabulary. 
Mancilla-Martinez et al.: Bilingual children's vocabulary development

7. The norms for the TVIP were developed over 20 years ago. To our knowledge, there is currently no other measure of very young children's receptive vocabulary knowledge in Spanish.

8. Bedore et al. (2005) used a similar procedure to classify Spanish-English bilingual language groups, but they worked with older children (ages 4-8) and relied on output per parent or teacher report or on grammaticality in target language on narrative storytelling task.

\section{REFERENCES}

Anderson, R. (2004). First language loss in Spanish-speaking children: Patterns of loss and implications for clinical practice. In B. Goldstein (Ed.) Bilingual language development and disorders in Spanish-English speakers (pp. 187-212). Baltimore, MD: Paul H. Brookes.

August, D., \& Shanahan, T. (2006) (Eds.), Developing literacy in second-language learners: Report of the National Literacy Panel on Language-Minority Children and Youth. Mahwah, NJ: Erlbaum.

Bedore, L. M., \& Peña, E. D. (2008). Assessment of bilingual children for identification of language impairment: Current findings and implications for practice. International Journal of Bilingual Education and Bilingualism, 11, 1-29.

Bedore, L. M., Peña, E. D., García, M., \& Cortez, C. (2005). Conceptual versus monolingual scoring: When does it make a difference? Language, Speech, and Hearing Services in Schools, 36, 188-200.

Boyce, L. K., Akers, J. F., Innocenti, M. S., Ortiz, E., \& Cook, G. A. (2008). Expressive vocabulary development of young Spanish-English bilingual children living in poverty. Manuscript submitted for publication, Utah State University.

Caesar, L. G., \& Kohler, P. D. (2007). The state of school-based bilingual assessment: Actual practice versus recommended guidelines. Language, Speech, and Hearing Services in Schools, 38, 190-200.

Dale, P. S., Fenson, L., \& Thal, D. (1993). Some suggestions for the adaptation of the MacArthur Communicative Development Inventories to additional languages. Unpublished manuscript. Retrieved from http://www.sci.sdsu.edu/cdi/suggestions_adapatations.htm

De Houwer, A. (1999). Environmental factors in early bilingual development: The role of parental beliefs and attitudes. In G. Extra \& L. Verhoeven (Eds.), Bilingualism and migration (pp. 75-96). New York: Mouton de Gruyter.

De Houwer, A., Bornstein, M. H., \& De Coster, S. (2006). Early understanding of two words for the same thing: a CDI study of lexical comprehension in infant bilinguals. International Journal of Bilingualism, 10, 331-347.

De Houwer, A., Bornstein, M. H., \& Leach, D. B. (2005). Assessing early communicative ability: A cross-reporter cumulative score for the MacArthur CDI. Journal of Child Language, 32, $735-758$.

Dunn, L. M., \& Dunn, L. M. (1997). Peabody Picture Vocabulary Test (3rd ed.). Minneapolis, MN: Pearson Assessments.

Dunn, L. M., Padilla, E. R., Lugo, D. E., \& Dunn, L. M. (1986). Test de Vocabulario en Imágenes Peabody. Circle Pine, MN: American Guidance Services.

Federal Register. (2008). The 2008 Health \& Human Services Poverty Guidelines. Retrieved March 14, 2008, from http://aspe.hhs.gov/poverty/08poverty.shtml

Feldman, H. M., Dollaghan, C. A., Campbell, T. F., Kurs-Lasky, M., Janosky, J. E., \& Paradise, J. L. (2000). Measurement properties of the MacArthur Communicative Development Inventories at ages one and two years. Child Development, 71, 310-322.

Fenson, L., Marchman, V. A., Thal, D. J., Dale, P. S., Reznick, J. S., \& Bates, E. (2007). MacArthur Communicative Development Inventories: User's guide and technical manual (2nd ed.). Baltimore, MD: Paul H. Brookes.

Grosjean, F. (1982). Life with two languages: An introduction to bilingualism. Cambridge, MA: Harvard University Press.

Grosjean, F. (1989). Neurolinguists, beware! The bilingual is not two monolinguals in one person. Brain and Language, 36, 3-15. 
Mancilla-Martinez et al.: Bilingual children's vocabulary development

Grosjean, F. (2008). Studying bilinguals. Oxford: Oxford University Press.

Hart, B., \& Risley, T. (1995). Meaningful differences in the everyday experience of young American children. Baltimore, MD: Paul H. Brookes.

Harwood, R. L., Leyendecker, B., Carlson, V. J., Asencio, M., \& Miller, A. (2002). Parenting among Latino families in the U.S. In M. H. Bornstein (Ed.), Handbook of parenting: Vol. 4. Social conditions and applied parenting (2nd ed., pp. 21-46). Mahwah, NJ: Erlbaum.

Hernandez, D. J., Denton, N. A., \& Macartney, S. E. (2008). Children in immigrant families: Looking into America's future. Social Policy Report, 3, 3-22.

Jackson-Maldonado, D., Thal, D. J., Fenson, L., Marchman, V. A., Newton, T., \& Conboy, B. (2003). MacArthur Inventarios del Desarollo de Habilidades Comunicativas: User's guide and technical manual. Baltimore, MD: Paul H. Brookes.

Leopold, W. (1939). Speech development of a bilingual child: A linguist's record: Vol. 1. Vocabulary growth in the first two years. Evanston, IL: Northwestern University Press.

Lesaux, N., Koda, K., Seigel, L., \& Shanahan, T. (2006). Development of literacy. In D. August \& T. Shanahan (Eds.), Developing literacy in second-language learners: Report of the National Literacy Panel on Language-Minority Children and Youth. Mahwah, NJ: Erlbaum.

Marchman, V. A. (1999). Scoring program for the MacArthur-Bates Communicative Development Inventories. Retrieved from http://www.sci.sdsu.edu/cdi/scoringdb_p.htm

Marchman, V. A., \& Martinez-Sussmann, C. (2002). Concurrent validity of caregiver/parent report measures of language for children who are learning both English and Spanish. Journal of Speech, Language \& Hearing Research, 45, 983-997.

Marchman, V. A., Martinez-Sussmann, C., \& Dale, P. S. (2004). The language-specific nature of grammatical development: Evidence from bilingual language learners. Developmental Science, 7, 212-224.

Mueller Gathercole, V. C., Thomas, E. M., \& Hughes, E. (2008). Designing a normed receptive vocabulary test for bilingual populations: A model from Welsh. The International Journal of Bilingual Education and Bilingualism, 11, 678-720.

National Institute of Child Health and Human Development, NIH DHHS. (2000). Report of the National Reading Panel: Teaching children to read (Report No. 00-4769). Washington, DC: US Government Printing Office.

Pan, B. A., Rowe, M. L., Spier, E., \& Tamis-LeMonda, C. (2004). Measuring productive vocabulary of toddlers in low-income families: Concurrent and predictive validity of three sources of data. Journal of Child Language, 31, 587-608.

Pearson, B. Z., \& Fernández, S. C. (1994). Patterns of interaction in the lexical growth in two languages of bilingual infants and toddlers. Language Learning, 44, 617-653.

Pearson, B. Z., Fernández, S. C., Lewedeg, V., \& Oller, D. K. (1997). The relation of input factors to lexical learning by bilingual infants. Applied Psycholinguistics, 18, 41-58.

Pearson, B. Z., Fernández, S. C., \& Oller, D. K. (1993). Lexical development in bilingual infants and toddlers: Comparison to monolingual norms. Language Learning, 43, 93-120.

Pearson, B. Z., Fernández, S. C., \& Oller, D. K. (1995). Cross-language synonyms in the lexicons of bilingual infants: One language or two? Journal of Child Language, 22, 345368.

Petitto, L. A., \& Holowka, S. (2002). Evaluating attributions of delay and confusion in young bilinguals: Special insights from infants acquiring a signed and a spoken language. Sign Language Studies, 3, 4-33.

Pew Hispanic Center. (2006). Statistical portrait of Hispanics in the United States, 2006 (table 22). Washington, DC: Author.

Rescorla, L., \& Achenbach, T. M. (2002). Use of the Language Development Survey (LDS) in a national probability sample of children 18 to 35 months old. Journal of Speech, Language, and Hearing Research, 45, 733-743.

Roberts, J. E., Burchinal, M., \& Durham, M. (1999). Parents' report of vocabulary and grammatical development of African American preschoolers: Child and environmental associations. Child Development, 70, 92-106.

Snow, C. E., Burns, M. S., \& Griffin, P. (1998) (Eds.), Preventing reading difficulties in young children. Washington, DC: National Academy Press.

Suarez-Orozco, M. M., \& Paez, M. M. (2002). Latinos: Remaking America. Berkeley, CA: University of California Press. 
Mancilla-Martinez et al.: Bilingual children's vocabulary development

Thal, D., Jackson-Maldonado, D., \& Acosta, D. (2000). Validity of a parent-report measure of vocabulary and grammar for Spanish-speaking toddlers. Journal of Speech, Language and Hearing Research, 43, 1087-1100.

US Department of Health and Human Services, Administration for Children and Families. (2007). Head Start Program Fact Sheet, fiscal year 2007. Retrieved from http://www.acf.hhs.gov/ programs/hsb/about/index.html\#factsheet

Vagh, S. B., Pan, B. A., \& Mancilla-Martinez, J. (2009). Measuring growth in bilingual and monolingual children's English productive vocabulary development: The utility of combining parent and teacher report. Child Development, 80, 1545-1563.

Woodcock, R. W. (1991). Woodcock Language Proficiency Battery-Revised. Itasca, IL: Riverside Publishing.

Woodcock, R. W., \& Muñoz-Sandoval, A. F. (1995). Bateria Woodcock-Muñoz Pruebas de Aprovechamieto-Evisada. Chicago: Riverside. 